\title{
Number of Spikes in Climbing Fibers Determines the Direction of Cerebellar Learning
}

\author{
Anders Rasmussen, ${ }^{1}$ Dan-Anders Jirenhed, ${ }^{1}$ Riccardo Zucca, ${ }^{1,2}$ Fredrik Johansson, ${ }^{1}$ Pär Svensson, ${ }^{1}$ and \\ Germund Hesslow ${ }^{1}$ \\ ${ }^{1}$ Associative Learning Group, Department of Experimental Medical Science, Lund University, 22184 Lund, Sweden, ${ }^{2}$ The Laboratory for Synthetic, \\ Perceptive, Emotive, and Cognitive Systems, Universitat Pompeu Fabra, 13808018 Barcelona, Spain
}

Cerebellar learning requires context information from mossy fibers and a teaching signal through the climbing fibers from the inferior olive. Although the inferior olive fires in bursts, virtually all studies have used a teaching signal consisting of a single pulse. Following a number of failed attempts to induce cerebellar learning in decerebrate ferrets with a nonburst signal, we tested the effect of varying the number of pulses in the climbing fiber teaching signal. The results show that training with a single pulse in a conditioning paradigm in vivo does not result in learning, but rather causes extinction of a previously learned response.

\section{Introduction}

The prevailing view of cerebellar learning is that climbing fiber (CF) impulses induce synaptic modification in the cerebellar cortex, such as long-term depression (LTD) of parallel fiber to Purkinje cell synapses. A much studied model of cerebellar learning is eyeblink conditioning, where repeated presentations of a neutral conditional stimulus (CS), often a tone, followed by a reflexeliciting unconditional stimulus (US), such as an air puff to the cornea, causes acquisition of a conditioned blink response (CR) (Gormezano et al., 1983). Eyeblink conditioning relies on the cerebellum (McCormick and Thompson, 1984), and acquisition of adaptively timed CRs requires the cerebellar cortex (Yeo et al., 1984; Hesslow and Yeo, 2002). During conditioning, Purkinje cells develop adaptively timed pause responses, "Purkinje cell CRs," thought to be the physiological basis of learned eyeblinks (Jirenhed et al., 2007; Jirenhed and Hesslow, 2011a). Results from microstimulation experiments suggest that Purkinje cells receive information about the CS via the mossy/parallel fiber pathway (Steinmetz et al., 1985; Hesslow et al., 1999), and information about the US via the CFs (Mauk et al., 1986; Jirenhed et al., 2007).

Purkinje cell CRs can disinhibit the cerebellar nuclei and, in extension, generate motor output (Hesslow and Yeo, 2002). In addition, disinhibition of the cerebellar nuclei causes increased inhibition of the inferior olive (IO), via the nucleo-olivary pathway (Bengtsson and Hesslow, 2006). Thus, the Purkinje cell CR

Received April 8, 2013; revised July 7, 2013; accepted July 12, 2013.

Author contributions: A.R., D.-A.J., and G.H. designed research; A.R., D.-A.J., R.Z., F.J., and P.S. performed research; A.R. and R.Z. analyzed data; A.R. and G.H. wrote the paper.

This work was supported by grants from the Swedish Research Council to the Linnaeus Centre for Cognition, Communication and Learning at Lund University (349-2007-8695) and to G. Hesslow (09899), and from the Krapperup, Söderberg, and Åhlen foundations.

The authors declare no competing financial interests.

Correspondence should be addressed to Anders Rasmussen, Associative Learning Group, Department of Experimental Medical Science, Lund University, Lund, Sweden. E-mail: anders.rasmussen@med.lu.se.

DOI:10.1523/JNEUROSCI.1527-13.2013

Copyright $\odot 2013$ the authors $\quad 0270-6474 / 13 / 3313436-05 \$ 15.00 / 0$ can potentially inhibit the IO and the US signal (Rasmussen et al., 2008).

Cells in the IO fire in high-frequency bursts $(>250 \mathrm{~Hz})$, typically consisting of one to six spikes (Armstrong and Rawson, 1979; Maruta et al., 2007; Mathy et al., 2009). Each spike elicits a corresponding EPSP in the Purkinje cell dendrite, but only a single complex spike will appear in extracellular recordings. Thus, additional spikes do not result in extra complex spikes, although they alter the appearance and duration of the complex spike (Mathy et al., 2009).

The burst nature of the IO response was discovered decades ago (Eccles et al., 1966), but virtually all research on cerebellar learning, in which climbing fibers were stimulated, has used single pulses as teaching signals, assuming they are of an "all-ornone" nature (Ito, 2001). Recently, the nature of the CF signal has received renewed interest and the bursting nature of the IO response has been reaffirmed several times (Maruta et al., 2007; Mathy et al., 2009).

Here we tested the effect of varying the number of climbing fiber stimulus pulses on the acquisition and extinction of Purkinje cell CRs. A burst-like stimulus reliably results in acquisition of Purkinje cell CRs. Here we show that single climbing fiber impulses do not result in learning, but actually cause extinction of previously acquired Purkinje cell CRs.

\section{Materials and Methods}

Surgery. Thirteen male ferrets were anesthetized in a mixture of $\mathrm{O}_{2}$ and air with $1.5-2 \%$ isoflurane (Baxter Medical), which was subsequently replaced intravenously by propofol. During anesthesia, a tracheotomy was performed, and the gas was led directly into a tracheal tube. The end expiratory $\mathrm{CO}_{2}$ concentration, arterial blood pressure, and rectal temperature were monitored and kept within physiological limits throughout the experiment. During the whole experiment, infusion was given intravenously $[50 \mathrm{mg} / \mathrm{ml}$ glucose and isotonic acetate Ringer's solution (proportion, 1:1) with $0.004 \mathrm{mg} / \mathrm{ml}$ albumin fraction $\mathrm{V}$ (from bovine serum; Sigma-Aldrich), $2 \mathrm{mg} / \mathrm{kg} / \mathrm{h}$ ]. After fixation of the head in a stereotaxic frame, the skull was opened on the left side, and the caudal half of the left cerebral hemisphere, together with a substantial part of the 

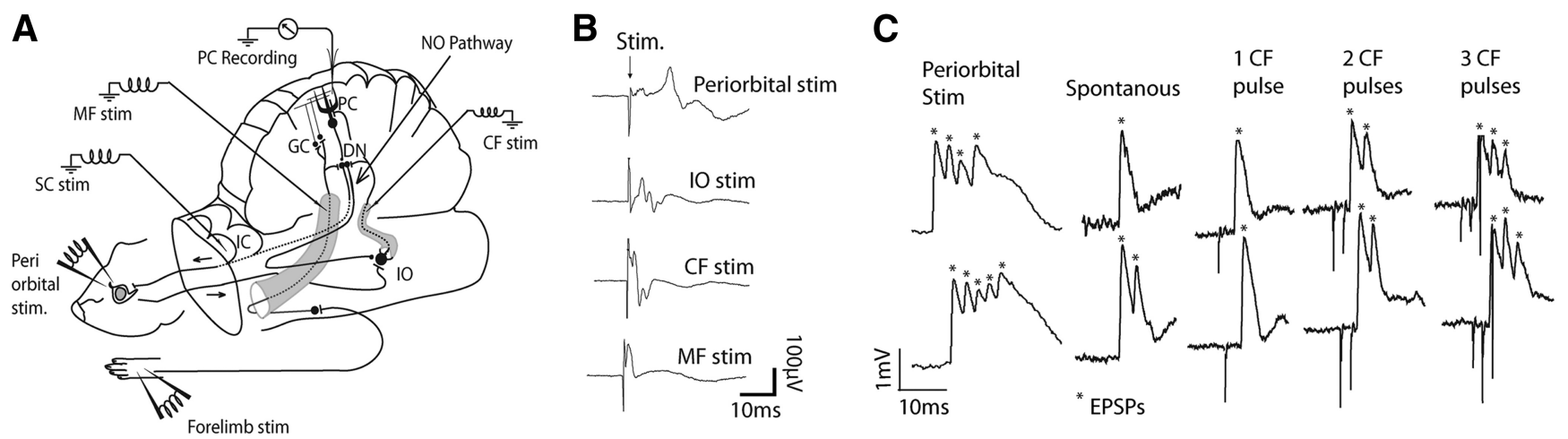

Figure 1. Experimental setup, field recordings, and intracellular recordings. A, Illustration of the experimental setup including relevant afferent and efferent cerebellar pathways. As the $C S$, we stimulated the forelimb, mossy fiber (MF), or superior colliculus (SC). As the US, we stimulated CFs. DN, Deep nuclei; GC, granule cell; NO, nucleo-olivary; PC, Purkinje cell. B, Typical examples of field potentials elicited on the cerebellar cortex following stimulation of cerebellar afferents. C, Representative sweeps from intracellular recordings showing that the number of elicited EPSPs in Purkinje cell dendrites corresponds to the number of stimulus pulses applied to the climbing fibers, and that peripheral, periorbital stimulation elicits multiple EPSPs.

thalamus on the left side, were removed by aspiration. The animals were decerebrated by sectioning the brainstem with a spatula $1-2 \mathrm{~mm}$ rostral to the superior colliculus. After decerebration, anesthesia was discontinued. With the cerebellum and colliculi exposed, a pool was constructed of cotton-reinforced agar and filled with warm high-density perfluorocarbon liquid (FC-40 Fluorinert; 3M). To ensure mechanical stability, animals were curarized, artificially ventilated, and kept hanging by the spine. A bilateral pneumothorax was performed to minimize chest movements and movements caused by changes in venous blood pressure. The dura covering the cerebellum was removed, and the surface was covered with agarose gel $(15 \mathrm{mg} / \mathrm{ml})$ to improve stability and prevent edema. This study was reviewed and approved by the local Swedish Ethical Committee.

Stimulation. Climbing fibers were stimulated in the ipsilateral inferior cerebellar peduncle by lowering an electrode $4.0-5.0 \mathrm{~mm}$ below the posterior cerebellar surface, at an angle of $45^{\circ}, 4 \mathrm{~mm}$ lateral to the midline and $4 \mathrm{~mm}$ rostral to the caudal border of the vermis. Mossy fibers in the ipsilateral middle cerebellar peduncle were stimulated with an electrode lowered into the brainstem through the inferior colliculus at an angle of $80^{\circ}, 1 \mathrm{~mm}$ medial to the lateral border of the inferior colliculus and at a depth of $4.0-5.0 \mathrm{~mm}$. The superior colliculus was stimulated by an electrode lowered $100 \mu \mathrm{m}$ below the surface of the middle of the superior colliculus at a $90^{\circ}$ angle. While tracking for climbing fibers and mossy fibers, single stimulus pulses were applied, and field potentials were recorded in the C3 zone of hemispheral lobule VI (HVI), identified by previously established criteria (Hesslow and Ivarsson, 1994; Hesslow, 1994; Fig. 1B). Direct stimulation of cerebellar afferents was done with tungsten electrodes (diameter, $30 \mu \mathrm{m}$; deinsulated tip, $50 \mu \mathrm{m}$ ). The effectiveness of all stimulation sites and stimulus intensities were verified again and adjusted if necessary, when recording the activity of single Purkinje cells.

Training protocol. The CS consisted of a $300 \mathrm{~ms}, 50 \mathrm{~Hz}$ train of stimuli applied to the ipsilateral forelimb skin (1.5-2.0 mA, $0.5 \mathrm{~ms})$, mossy fibers, or the superior colliculus (in both cases, $90-200 \mu \mathrm{A}, 0.1 \mathrm{~ms}$ ). Before the switch to a single pulse was made, the US consisted of two $10 \mathrm{~ms}$ stimulus trains delivered with a $20 \mathrm{~ms}$ interval, each consisting of five impulses at $500 \mathrm{~Hz}$, applied to the ipsilateral climbing fibers $(15-90 \mu \mathrm{A}$, $0.1 \mathrm{~ms}$ pulse duration). A burst-like stimulus was used because it better resembles the natural firing pattern of the IO (Maruta et al., 2007; Mathy et al., 2009), and because this type of stimulation reliably results in acquisition of Purkinje cell CRs (Jirenhed et al., 2007). When a Purkinje cell CR had been acquired, we switched to single-pulse climbing fiber stimulation, whereas other parameters remained constant. In some cells we switched back and forth between a US consisting of a single-pulse CF stimulus and a US consisting of two sets of five impulses. On one occasion, instead of switching back to two sets of five impulses, we switched to two impulses at $500 \mathrm{~Hz}$ and then to three impulses so that we could establish the threshold at which the climbing fiber signal induces learning. If at any point a cell was lost, we searched for another one. If another
Purkinje cell that satisfied the inclusion criteria was found, we first determined whether the cell exhibited Purkinje cell CRs in response to the CS. If CRs were present, we continued training with the CS paired with a single-pulse CF stimulus. If Purkinje cell CRs were absent, we resumed training with the CS paired with a burst-like US. For intracellular recordings, which rarely lasted $>60 \mathrm{~s}$, the protocol consisted of one, two, or three stimulus pulses applied to the climbing fibers at $500 \mathrm{~Hz}$, with $1 \mathrm{~s}$ between each burst.

Purkinje cell recordings. Extracellular single-unit recordings of Purkinje cells, identified by the presence of complex spikes, were performed using quartz glass-coated platinum-tungsten fiber microelectrodes with pulled and ground tips (30-40 $\mu \mathrm{m}$ metal core diameter; Thomas Recording). All Purkinje cells were located in a blink-controlling area of the C3 zone of the ipsilateral HVI. To be included in the data set, the Purkinje cell had to satisfy the following criteria: (1) confirmed periorbital climbing fiber input with a latency of $<15 \mathrm{~ms}$, (2) confirmed climbing fiber input from the inferior cerebellar peduncle with a latency of $\sim 2$ $\mathrm{ms}$, and (3) sufficient recording stability to demonstrate a change in the response to CS during training. Intracellular Purkinje cell recordings $(n=3)$ were performed using pulled micropipettes filled with $\mathrm{KNO}_{3}$ (impedance, 10-20 M $\Omega$ ). Recorded electrical signals were passed unfiltered through an amplifier and a Power1401 data acquisition analog-to-digital converter unit (Cambridge Electronics Design). The sampling rate was $40 \mathrm{kHz}$.

Data analysis. All spike sorting was performed using Spike2, version 7 (Cambridge Electronics Design), and subsequent data analysis was performed in custom Matlab software (MathWorks). To separate simple and complex spikes, we used template matching in Spike2 followed by visual inspection. Purkinje cell background-firing rates vary over time. To avoid misclassifying naturally occurring decreases in simple spike activity as Purkinje cell CRs, all analysis was based on normalized simple spike firing during the CS period. To calculate the normalized simple spike firing, we divided the simple spike frequency within the CS period with the frequency in the $600 \mathrm{~ms}$ before CS onset. Since reextinction in general required fewer trials than extinction, we also normalized the number of paired trials that had been given; that is, instead of using the absolute number of paired presentations, we looked at the percentage of completed training of the training had been completed. To test whether the change in simple spike firing following training with a single climbing fiber impulse was statistically significant, we used a nonparametric Wilcoxon matched-pairs signed rank test.

\section{Results}

The decerebrate ferret preparation (Fig. 1A) has several advantages when studying the mechanisms of eyeblink conditioning. Though the cell recordings presented here are from paralyzed animals, decerebrate ferrets can acquire conditioned eyeblinks (Hesslow et al., 1999; Hesslow and Yeo, 2002), meaning that the 
A

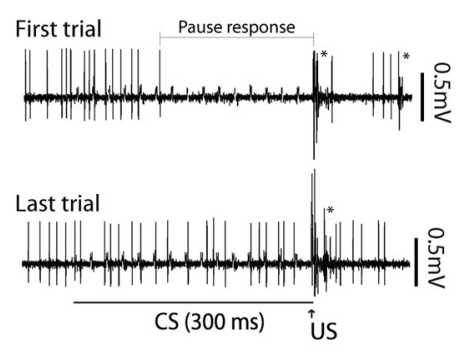

D

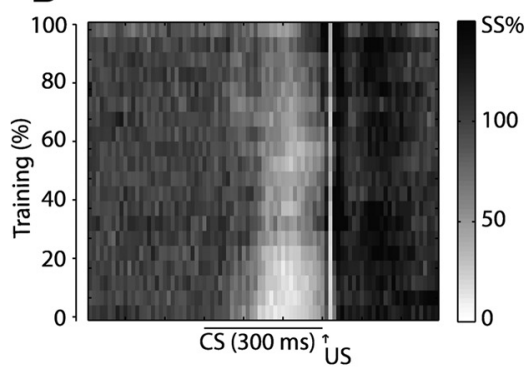

B

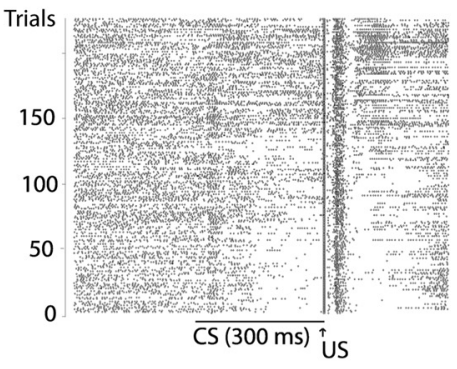

E

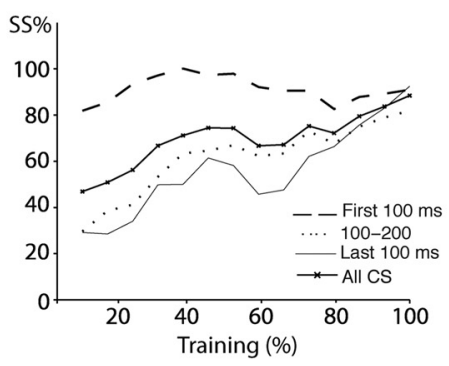

C

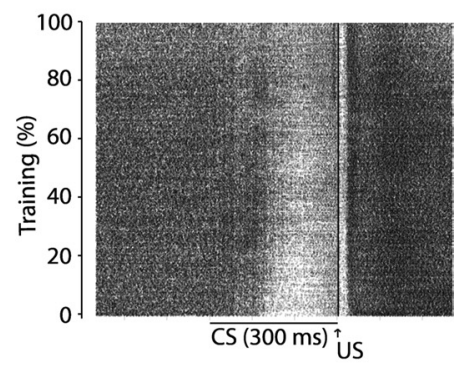

F

Figure 2. A single-pulse CF stimulus results in extinction of the Purkinje cell CR. $A$, Extracellular Purkinje cell recording from a single cell showing responses to the conditional stimulus before and after training with a single stimulus pulse. $\boldsymbol{B}$, Raster plot showing the gradual extinction of a Purkinje cell CR during training with a single stimulus pulse. The acquired pause response initially appears to last beyond the US, and as the pause response is extinguished it is replaced by a US-induced excitation. Each dot represents one simple spike in the extracellular record, and each line represents one trial. C, Composite raster plot merging raster plots from all cells (15 sessions from 13 cells), laid on top of each other. The $y$-axis was adjusted according to the length of the recording because the time it took before the Purkinje cell CR had been extinguished varied from cell to cell. $\boldsymbol{D}$, Normalized raster plot based on all cells trained with a single stimulus pulse. The darkness of each square in the raster plot represents the average simple spike frequency in a 10 trial, 10 ms bin divided by the average background frequency in the same bin. $\boldsymbol{E}$, Line diagram illustrating changes in simple spike firing in different parts of the CS-US interval during training. Whereas there is little change in simple spike firing in the first $100 \mathrm{~ms}$ of the CS US interval, the latter part of the CS, and especially the last $100 \mathrm{~ms}$ of the $C S$, is associated with a substantial increase in simple spike firing during trained. Averaging the activity in the whole $C S$ period also reveals an effect of training on simple spike activity. $\boldsymbol{F}$, Box plot showing how much cells increased their firing in the whole $C S$ during training with a single-pulse stimulus. The change in simple spike firing was calculated by subtracting the average simple spike firing in the last $5 \%$ trials of each cell with the activity in the first $5 \%$ trials of each cell.

neural network responsible for this learning remains intact. The relative stability of the setup allows for long single-unit recordings, which are necessary to follow the acquisition or extinction of Purkinje cell CRs. In addition, anesthesia can be excluded.

When we first tested IO/CF stimulation as a teaching signal, we used a protocol analogous to that which induces learning with a periorbital US (three pulses; $100-300 \mu \mathrm{A} ; 20 \mathrm{~ms}$ pulse interval, $50 \mathrm{~Hz} ; 0.1 \mathrm{~ms}$ pulse duration). Although we always verified that CF stimulation elicited complex spikes in the Purkinje cell, this training protocol, with a nonburst CF stimulus, failed to induce any Purkinje cell CRs in nine consecutive experiments. To ensure that single CF pulses were indeed transmitted to the Purkinje cells and that these results not merely reflected insufficient signal strength, we used micropipettes to record EPSPs in Purkinje cell dendrites following one, two, or three CF stimulus pulses. The results confirmed that the number of EPSPs elicited corresponded to the number of CF stimulus pulses applied (Fig. 1C), which is also consistent with previous research (Mathy et al., 2009).

After these nine failed attempts to obtain acquisition of Purkinje cell CRs, we switched to a teaching signal that more resembled normal IO firing (Eccles et al., 1966; Maruta et al., 2007; Mathy et al., 2009), namely, two $500 \mathrm{~Hz}$ bursts with five stimuli in each. This reliably resulted in acquisition of Purkinje cell CRs (Jirenhed et al., 2007). Subsequently, nearly all Purkinje cells (more than 100 cells), provided they had input from the relevant climbing fibers and mossy/parallel fibers, acquired Purkinje cell CRs when using climbing fiber burst stimulation as the US.
Motivated by the observation that two sets of five CF pulses at $500 \mathrm{~Hz}$ resulted in learning, whereas three pulses at $50 \mathrm{~Hz}$ did not, we designed an experiment to test how the number of CF pulses in the US affects the acquisition and extinction of Purkinje cell CRs. Animals were conditioned with a US consisting of two sets of five pulses at $500 \mathrm{~Hz}(200-700 \mu \mathrm{A})$, delivered to the CF, paired with a CS consisting of a $300 \mathrm{~ms}$ pulse train at $50 \mathrm{~Hz}$, delivered to the ipsilateral forelimb $(n=8 ; 0.6-1.5 \mathrm{~mA} ; 1 \mathrm{~ms})$, mossy fibers $(n=3 ; 100 \mu \mathrm{A} ; 0.1 \mathrm{~ms})$, or superior colliculus $(n=1 ; 150 \mu \mathrm{A} ; 0.1$ $\mathrm{ms})$. When a Purkinje cell CR had been acquired, we switched from a burst to a single-pulse climbing fiber stimulus. Other variables were kept constant.

Fifteen sessions from 13 cells were recorded using a singlepulse CF stimulus after Purkinje cell CRs had been acquired. On three occasions, the recording was sufficiently long lasting to allow us to later switch back to a burst US, and then to a single pulse again. In 12 of 15 sessions, training with a single pulse CF stimulus resulted in extinction of the Purkinje cell CR (an increase in simple spike firing during the CS; Fig. 2). In two sessions there was no change in simple spike activity, and in one session there was a decrease in simple spike activity. The median change in simple spike activity was $41 \%$, ranging from -17 to $116 \%$ (Fig. $2 F)$. A Wilcoxon matched-pairs signed rank test confirmed that the simple spike frequency increased significantly during training with a single pulse ( $W=104 ; p=0.0015)$. Consistent with previous findings (Jirenhed et al., 2007; Jirenhed and Hesslow, 2011a,b), and with behavior (Gormezano et al., 1983), the de- 


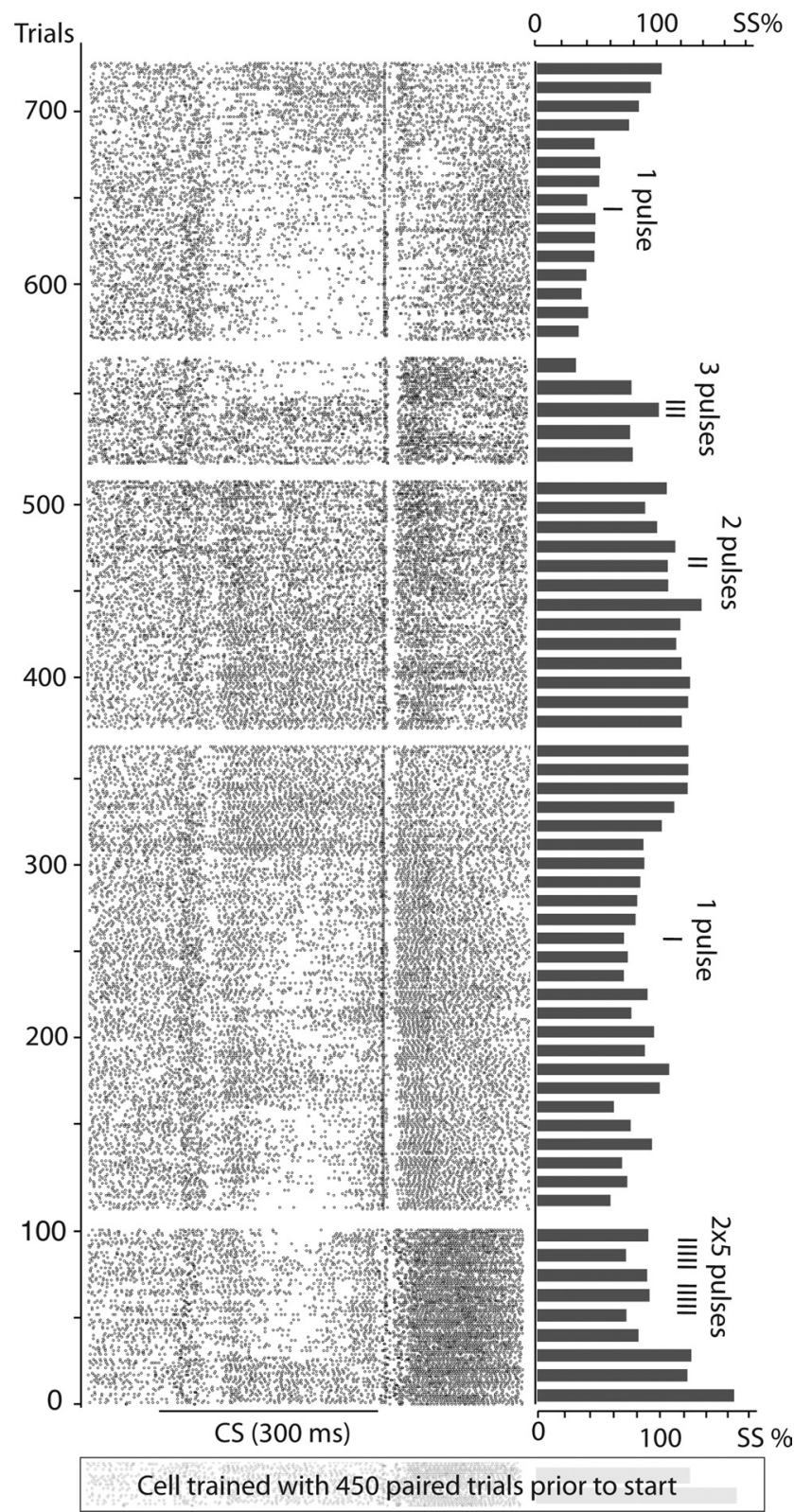

Figure 3. Raster plot depicting simple spike firing in a single cell throughout several cycles in which different numbers of stimulus pulses were used as teaching signals. When found, the cell had already received $450 \mathrm{CS}$ and US presentations, which explains why the acquisition of the Purkinje cell CR was seen after $<50$ trials. Switching from a burst-like teaching signal (two sets of five pulses at $500 \mathrm{~Hz}$ ) to a single pulse resulted in a typical extinction process; i.e., the simple spike pause response during the $C S$ disappeared. Going up to two pulses had no effect on the Purkinje cell CR, but going up to three pulses resulted in swift reacquisition of the Purkinje cell CR. Finally, going back to one pulse again resulted in extinction.

crease and subsequent increase in simple spike firing was most pronounced toward the end of the CS (Fig. 2E).

The US threshold for induction of a Purkinje cell CR was defined in one Purkinje cell initially trained with a forelimb CS $(50 \mathrm{~Hz}, 1$ $\mathrm{mA})$, paired with two sets of five $500 \mathrm{~Hz}$ CF pulses $(230 \mu \mathrm{A})$, until a Purkinje cell CR had been acquired. As expected, a single-pulse US caused extinction of the Purkinje cell CR. Increasing the number of pulses to two $(500 \mathrm{~Hz})$ did not result in reacquisition. However, three pulses $(500 \mathrm{~Hz})$ did result in reacquisition, and switching back to one pulse caused reextinction of the response (Fig. 3). This suggests that the equilibrium level is close to two spikes.
Occasionally, climbing fiber stimulation elicited simple spikes, possibly because of antidromic activation of mossy fiber collaterals. However, the rate of acquisition appears to be independent of this increase in simple spikes. Burst activation of climbing fibers or the inferior olive consistently results in Purkinje cell CRs, even if no simple spikes are elicited (Jirenhed et al., 2007). It is therefore unlikely that this increase in simple spike firing affected the present results.

\section{Discussion}

We have demonstrated that a US, or teaching signal, consisting of a single climbing fiber stimulus causes extinction, not acquisition, of a Purkinje cell CR. This was not because the stimulus failed to activate the climbing fibers since we always confirmed that the CF stimulus elicited a complex spike in the Purkinje cell. These results challenge the interpretation of research on cerebellar learning where an all-or-none teaching signal has been assumed (Ito, 2001).

For example, several studies have suggested that LTD, which is induced by pairing parallel fiber stimulation with CF stimulation, is the synaptic mechanism responsible for classical conditioning (Ito, 2001; Koekkoek et al., 2003). However, a single CF impulse, which has been shown to be sufficient for LTD induction (Ito et al., 1982; Ekerot and Kano, 1985; Ito, 2001), actually causes extinction of Purkinje cell CRs. These results, together with additional physiological evidence (Hesslow et al., 2013) as well as evidence from transgenic mice (Schonewille et al., 2011), suggest that LTD is not the critical mechanism for conditioning, although it is still possible that LTP plays an important role (Schonewille et al., 2010). In contrast to the LTD studies cited above, Mathy et al. (2009) observed potentiation of the parallel fiber-Purkinje cell synapse when pairing parallel fiber stimulation with a single CF impulse. Only when a CF burst was used did they get LTD. These recent discoveries, and the results presented in the present paper, raise some intriguing questions concerning the plastic changes underlying cerebellar learning. To what extent are depression and potentiation of the parallel fiber-Purkinje cell synapses responsible for the acquisition of Purkinje cell CRs, and for cerebellar learning in general? If depression and potentiation, which are induced within minutes of applying the stimulation protocol, are the underlying mechanisms of cerebellar learning, then why does acquisition of conditioned eyeblinks and Purkinje cell CRs take several hours? How exactly does the number of spikes in the climbing fiber signal influence the type of plasticity induced in the cerebellar cortex? These important questions should be addressed in future studies.

The reason that single CF impulses are insufficient to induce cerebellar learning may have to do with the fact that the IO serves multiple purposes. One function of the IO, besides relaying the teaching signal, is to regulate background activity in the cerebellar circuit (Cerminara and Rawson, 2004; Bengtsson and Hesslow, 2013). Interfering with the IO's normal firing pattern has striking effects on cortical activity and, consequently, on cerebellar output (Bengtsson et al., 2004; Zbarska et al., 2007). Thus, to maintain normal functioning of the cerebellar network, it may be advantageous if modulation of learning only requires slight alterations of IO activity.

Furthermore, if a periorbital stimulus can generate a burst of CF spikes (Fig. 1C), then the Purkinje cell CR, through inhibition of the IO, could reduce the number of CF spikes and consequently the number of EPSPs generated by the US. Thus, the negative feedback exerted by the Purkinje cell CR on the IO (Hesslow and Yeo, 2002; Bengtsson and Hesslow, 2006; Rasmussen et 
al., 2008) may be able to push the strength of the US signal below the learning threshold. This would allow the cerebellar circuit to reach an equilibrium where the negative feedback from the Purkinje cell CR matches the strength of the teaching signal, thus preventing runaway synaptic plasticity in the cortex (Lepora et al., 2010). It would also explain why lowering the US intensity can lead to extinction of overt CRs (Kehoe and White, 2002). As long as the negative feedback generated by the Purkinje cell CR matches the strength of the US signal, neither acquisition nor extinction ought to occur. However, if the US intensity is reduced, the Purkinje cell CR could suppress the US signal below the learning threshold, causing extinction.

Placing our results in a broader context invites comparisons with learning in the hippocampus, where it has been known for a long time that opposite forms of plasticity can be induced by slight alterations of stimulus parameters (Malenka and Bear, 2004). In a similar manner, and consistent with the nonlinear relationship between cerebellar plasticity and calcium release in Purkinje cells (Vogt and Canepari, 2010), our results demonstrate that the exact stimulus parameters used determines whether you get acquisition or extinction of the Purkinje cell CR.

\section{References}

Armstrong DM, Rawson JA (1979) Activity patterns of cerebellar cortical neurones and climbing fibre afferents in the awake cat. J Physiol 289:425448. Medline

Bengtsson F, Hesslow G (2006) Cerebellar control of the inferior olive. Cerebellum 5:7-14. CrossRef Medline

Bengtsson F, Hesslow G (2013) Feedback control in the olivo-cerebellar loop. In: The handbook of the cerebellum and cerebellar disorders (Manto MU, Gruol DL, Schmahmann JD, Koibuchi N, Rossi F, eds), pp 1079-1099. Dordrecht, The Netherlands: Springer.

Bengtsson F, Svensson P, Hesslow G (2004) Feedback control of Purkinje cell activity by the cerebello-olivary pathway. Eur J Neurosci 20:2999-3005. CrossRef Medline

Cerminara NL, Rawson JA (2004) Evidence that climbing fibers control an intrinsic spike generator in cerebellar Purkinje cells. J Neurosci 24:4510-4517. CrossRef Medline

Eccles JCC, Llinás R, Sasaki K (1966) The excitatory synaptic action of climbing fibres on the Purkinje cells of the cerebellum. J Physiol 182:268296. Medline

Ekerot CF, Kano M (1985) Long-term depression of parallel fibre synapses following stimulation of climbing fibres. Brain Res 342:357-360. CrossRef Medline

Gormezano I, Kehoe EJ, Marshall B (1983) Twenty years of classical conditioning research with the rabbit. Prog Psychobiol Physiol Psychol 10:197-275

Hesslow G (1994) Inhibition of classically conditioned eyeblink responses by stimulation of the cerebellar cortex in the decerebrate cat. J Physiol 476:245-256. Medline

Hesslow G, Ivarsson M (1994) Suppression of cerebellar Purkinje cells during conditioned responses in ferrets. Neuroreport 5:649-652. CrossRef Medline

Hesslow G, Yeo CH (2002) The functional anatomy of skeletal conditioning. In: A neuroscientist's guide to classical conditioning (Moore JW, ed), pp 86-146.

Hesslow G, Svensson P, Ivarsson M (1999) Learned movements elicited by direct stimulation of cerebellar mossy fiber afferents. Neuron 24: 179-185. CrossRef Medline

Hesslow G, Jirenhed D, Rasmussen A, Johansson F (2013) Classical condi- tioning of motor responses: what is the learning mechanism? Neural Netw pii: S0893-6080(13)00098-1. CrossRef Medline

Ito M (2001) Cerebellar long-term depression: characterization, signal transduction, and functional roles. Physiol Rev 81:1143-1195. Medline

Ito M, Sakurai M, Tongroach P (1982) Climbing fibre induced depression of both mossy fibre responsiveness and glutamate sensitivity of cerebellar Purkinje cells. J Physiol 324:113-134. Medline

Jirenhed DA, Hesslow G (2011a) Learning stimulus intervals-adaptive timing of conditioned Purkinje cell responses. Cerebellum 10:523-535. CrossRef Medline

Jirenhed DA, Hesslow G (2011b) Time course of classically conditioned Purkinje cell response is determined by initial part of conditioned stimulus. J Neurosci 31:9070-9074. CrossRef Medline

Jirenhed DA, Bengtsson F, Hesslow G (2007) Acquisition, extinction, and reacquisition of a cerebellar cortical memory trace. J Neurosci 27:2493-2502. CrossRef Medline

Kehoe EJ, White NE (2002) Extinction revisited: similarities between extinction and reductions in US intensity in classical conditioning of the rabbit's nictitating membrane response. Anim Learn Behav 30:96-111. CrossRef Medline

Koekkoek SK, Hulscher HC, Dortland BR, Hensbroek RA, Elgersma Y, Ruigrok TJ, De Zeeuw CI (2003) Cerebellar LTD and learning-dependent timing of conditioned eyelid responses. Science 301:1736-1739. CrossRef Medline

Lepora NF, Porrill J, Yeo CH, Dean P (2010) Sensory prediction or motor control? Application of marr-albus type models of cerebellar function to classical conditioning. Front Comput Neurosci 4:140. Medline

Malenka RC, Bear MF (2004) LTP and LTD: an embarrassment of riches. Neuron 44:5-21. CrossRef Medline

Maruta J, Hensbroek RA, Simpson JI (2007) Intraburst and interburst signaling by climbing fibers. J Neurosci 27:11263-11270. CrossRef Medline

Mathy A, Ho SS, Davie JT, Duguid IC, Clark BA, Häusser M (2009) Encoding of oscillations by axonal bursts in inferior olive neurons. Neuron 62:388-399. CrossRef Medline

Mauk MD, Steinmetz JE, Thompson RF (1986) Classical conditioning using stimulation of the inferior olive as the unconditioned stimulus. Proc Natl Acad Sci U S A 83:5349-5353. CrossRef Medline

McCormick DA, Thompson RF (1984) Cerebellum: essential involvement in the classically conditioned eyelid response. Science 223:296-299. CrossRef Medline

Rasmussen A, Jirenhed DA, Hesslow G (2008) Simple and complex spike firing patterns in Purkinje cells during classical conditioning. Cerebellum 7:563-566. CrossRef Medline

Schonewille M, Belmeguenai A, Koekkoek SK, Houtman SH, Boele HJ, van Beugen BJ, Gao Z, Badura A, Ohtsuki G, Amerika WE, Hosy E, Hoebeek FE, Elgersma Y, Hansel C, De Zeeuw CI (2010) Purkinje cell-specific knockout of the protein phosphatase $\mathrm{PP} 2 \mathrm{~B}$ impairs potentiation and cerebellar motor learning. Neuron 67:618-628. CrossRef Medline

Schonewille M, Gao Z, Boele HJ, Vinueza Veloz MF, Amerika WE, Simek AA, De Jeu MT, Steinberg JP, Takamiya K, Hoebeek FE, Linden DJ, Huganir RL, De Zeeuw CI (2011) Reevaluating the role of LTD in cerebellar motor learning. Neuron 70:43-50. CrossRef Medline

Steinmetz JE, Lavond DG, Thompson RF (1985) Classical conditioning of the rabbit eyelid response with mossy fiber stimulation as the conditioned stimulus. Bull Psychonom Soc 23:245-248.

Vogt KE, Canepari M (2010) On the induction of postsynaptic granule cellPurkinje neuron LTP and LTD. Cerebellum 9:284-290. CrossRef Medline

Yeo CH, Hardiman MJ, Glickstein M (1984) Discrete lesions of the cerebellar cortex abolish the classically conditioned nictitating membrane response of the rabbit. Behav Brain Res 13:261-266. CrossRef Medline

Zbarska S, Holland EA, Bloedel JR, Bracha V (2007) Inferior olivary inactivation abolishes conditioned eyeblinks: extinction or cerebellar malfunction? Behav Brain Res 178:128-138. CrossRef Medline 